\title{
Varietal effect in perennial ryegrass on milk productivity of dairy cows in continuous grazing: turf variety vs forage variety
}

\author{
L Hazard, JC Emile, X Charrier, M Ghesquière \\ INRA Station d'Amélioration des Plantes Fourragères, 86600 Lusignan, France
}

\begin{abstract}
A turf and a diploid forage variety were tested on animal production and compared to varietal difference in DM yield previously established under both infrequent cutting (IC : every 5 weeks) and frequent cutting (FC : every week) (Hazard, 1995, PhD thesis).
\end{abstract}

At the autumn 1990, two paddocks of four hectares each were sown with a turf variety and a forage variety of perennial ryegrass. Both paddocks were grazed from 12 April to 3 June 1994 by two groups of dairy cows in end lactation. Both paddocks were similarly managed : the stoking rate at the beginning of the experiment was 24 cows per paddock and 18 cows per paddock after 7 may. Milk productivity was recorded every day. The canopy height was estimated from 200 measurements per paddocks every week.

Milk yield was $1.3 \%$ higher when the forage variety was grazed compared to the turf variety. The larger DM yield for the forage variety than for the turf variety when estimated under infrequent cutting (14.3 vs $12.6 \mathrm{t} / \mathrm{ha}$ ) did not lead to a difference of the same range on the milk productivity. As a matter of fact, frequent cutting gave a better estimation of the varietal difference. But DM yield of the forage variety under frequent cutting was still $5 \%$ higher than that of the turf variety. The canopy height of the turf was lower and more homogeneous than that of the forage variety since the cows grazed longer and deeper in the turf canopy. Moreover, since high herbage mass is associated with reduced herbage digestibility (Stakelum and Dillon, XVI Intern Grassid Cong, Nice, France, 1157-1158), the turf variety could be more digestible than the forage one, which compensated for its lower DM yield.

This experiment enlightened the difficulty to detect between-cultivar differences in animal production. The paddocks need to be intensively grazed and the stocking rate closely adjust to the cultivar morphogenesis in order to obtain valuable comparisons between cultivars.

Although growing in a contrasting way, the turf variety led to almost the same milk production than the forage variety. This result is promising since selection based on morphogenetic components had already resulted in genotypes which showed a productivity $15 \%$ higher under frequent cutting than that of turf controls but having a similar canopy architecture (Hazard and Ghesquière, submitted to Grass For Sci). Regarding genetic variability in ryegrass, from turf to current forage varieties, those selected genotypes could correspond to an optimum of animal production under grazing.

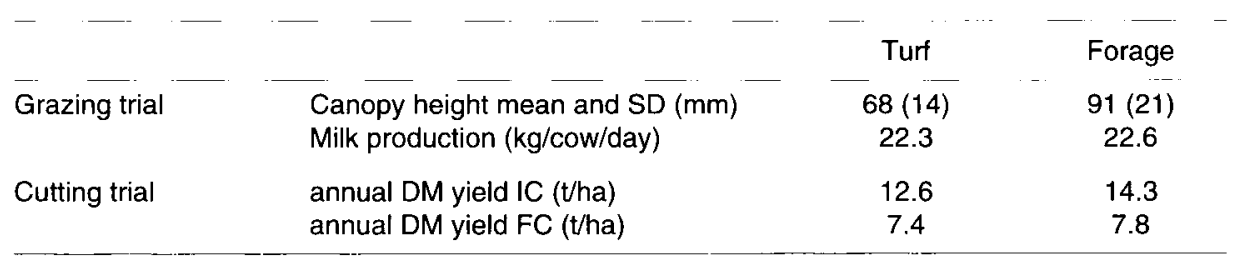

